\title{
Effect of urokinase-type plasminogen activator system in gastric cancer with peritoneal metastasis
}

\author{
YOUCHENG DING $^{1}$, HUI ZHANG ${ }^{1}$, AIGUO LU ${ }^{1}$, ZHUQING ZHOU $^{1}$, MINGAN ZHONG $^{1}$, \\ DONGWEI SHEN ${ }^{1}$, XUJING WANG ${ }^{1}$ and ZHENGGANG ZHU ${ }^{2}$ \\ ${ }^{1}$ Department of General Surgery, Shanghai East Hospital Affiliated to Tongji University, Shanghai 200120; \\ ${ }^{2}$ Department of Gastroenterological Surgery, Ruijin Hospital, Shanghai Jiao Tong University School of Medicine, \\ Shanghai 200025, P.R. China
}

Received February 26, 2015; Accepted January 6, 2016

DOI: $10.3892 / 01.2016 .4498$

\begin{abstract}
Peritoneal metastasis is a primary cause of mortality in patients with gastric cancer. Urokinase-type plasminogen activator (UPA) has been demonstrated to be associated with tumor cell metastasis through the degradation of the extracellular matrix. The present study aimed to investigate the mechanisms of the uPA system in gastric cancer with peritoneal metastasis. Expression of uPA, uPA receptor (uPAR) and plasminogen activator inhibitor-1 (PAI-1) in four gastric cell lines (AGS, SGC7901, MKN45 and MKN28) was measured by semiquantitative reverse transcription polymerase chain reaction, enzyme-linked immunosorbent assay and western blotting. uPA activity was detected using a uPA activity kit. Peritoneal implantation models of rats were established by injecting four gastric cancer cell lines for the selection of the cancer cells with a high planting potential. Biological behaviors, including adhesion, migration and invasion, were determined using a methyl thiazolyl tetrazolium assay. Expression of the uPA system was observed to be highest in the SGC7901 cells among the four gastric cell lines. uPA activity
\end{abstract}

Correspondence to: Dr Zhenggang Zhu, Department of Gastroenterological Surgery, Ruijin Hospital, Shanghai Jiao Tong University School of Medicine, 197 Ruijin Road II, Shanghai 200025, P.R. China

E-mail: zhzhgg8@163.com

Dr Hui Zhang, Department of General Surgery, Shanghai East Hospital Affiliated to Tongji University 150 Jimo Road, Pudong New Area, Shanghai 200120, P.R. China

E-mail: zhangv_hui@163.com

Abbreviations: uPA, urokinase-type plasminogen activator; ECM, extracellular matrix; uPAR, uPA receptor; PAI-1, plasminogen activator inhibitor-1; PIg, plasminogen; SF-CM, serum-free media; MTT, methyl thiazolyl tetrazolium; MAPK, mitogen-activated protein kinase

Key words: urokinase-type plasminogen activator, peritoneal metastasis, gastric cancer was observed to be highest in the MKN45 cells and lowest in the AGS cells. Furthermore, peritoneal implantation analysis demonstrated that no peritoneal tumors were identified in the AGS cells, whilst the tumor masses observed in the SGC7901 and MKN45 cells were of different sizes. The survival times of the rats injected with the MKN28 and SGC7901 cells were longer than those of the rats injected with the MKN45 cells. Antibodies for UPA, uPAR and PAI-1 in the UPA system had the ability to inhibit the adhesion, migration and invasion of peritoneal metastasis in the gastric cancer cells. The results of the present study demonstrated that the uPA system was positively associated with peritoneal metastasis in gastric cancer.

\section{Introduction}

Generally, the worldwide incidence and mortality rates of gastric cancer have decreased substantially over the last few decades (1). However, in China, even following curative resection, patients with advanced gastric cancer continue to have an adverse prognosis (2). The current medical management of patients with gastric cancer is not satisfactory, and the great expense of the treatment places a large economic burden on the family of the patient and on society.

Peritoneal metastasis is a common pattern of spread that is observed in gastric cancer, with its occurrence leading to malignant ascites, intestinal obstruction and emaciation, the major cause of gastric cancer-associated mortality $(3,4)$. Preliminary research has demonstrated that tumor invasion and metastasis to the peritoneum has a close association with gastric cancer. Two major theories of tumor carcinogenesis have been proposed: i) Epithelial-mesenchymal transition, which reduces adhesion between tumor cells, results in metastasis during the embryonic period (5); and ii) the subsets of cancer stem cells (like stem cells), which have the capacity to self-renew, self-differentiate and control a steady state, contribute to cell metastasis (6). Degradation of the extracellular matrix (ECM) is a precondition required for tumor invasion and metastasis (7). In a study by Steeg (8), it was reported that tumor cells are required to translocate out of the primary foci and adhere to proteins bound to cell surface receptors in the basement membrane and ECM; this allows the cell to invade the ECM. Peritoneal metastasis is random 
and unpredictable, primarily due to the large surface area and full disease spread over the peritoneal tissue in the abdominal cavity (9). Despite numerous studies providing evidence that tumor metastasis is associated with gastric cancer, the mechanisms of gastric cancer with peritoneal metastasis have not yet been fully discussed.

It has been reported that the urokinase-type plasminogen activator (uPA) system is associated with the differentiation, stages, pathology and prognosis of gastric cancer. As a protease, uPA participates in the degradation of the ECM and serves a crucial role in tumor metastasis (10). uPA receptor (UPAR), plasminogen activator inhibitor-1 (PAI-1) and plasminogen (PIg) are the key members within the uPA system (11). It has been demonstrated that uPA is a primary factor required for the processes of tumor invasion and metastasis. For example, Pulukuri and Rao (12) reported that the silent expression of uPA inhibits the internal invasion and vessel formation of tumor cells in prostate cancer. Dass et al (13) also demonstrated that the silent expression of uPA in lung cancer cells inhibits the hyperplasia of tumor cells and pulmonary metastasis (13). Kaneko et al (14) reported that UPAR and vascular endothelial growth factor can contribute synergistically to tumor progression in gastric cancer. Furthermore, Lee et al (15) observed that PAI-1 induces the invasive behavior of gastric cancer cells by upregulating the uPA system.

Despite numerous studies demonstrating an association between the uPA system and gastric cancer, few studies have confirmed an association between the uPA system and peritoneal metastasis in gastric cancer. In the present study, the expression level and enzyme activity of the uPA system was analyzed in four different gastric cancer cell lines, and the peritoneal implantation capability of the four cell lines was subsequently compared in rats. Additionally, the effect of the uPA system on the biological behaviors (including adhesion, migration and invasion) of peritoneal cells in gastric cancer was studied in vitro. Overall, the present study aimed to investigate the mechanisms of the uPA system in peritoneal metastasis and confirm the diagnostic significance of the uPA system in gastric cancer.

\section{Materials and methods}

Cell culture. The human gastric cancer cell lines, AGS, SGC7901, MKN45 and MKN28, with varying differentiation degrees, and the peritoneal mesothelial cell line, HMrSV5, were donated by the Department of Nephrology, Shanghai First People's Hospital (Shanghai, China). Gastric cancer cells were maintained in Roswell Park Memorial Institute (RPMI) 1640 medium (Gibco; Thermo Fisher Scientific, Inc., Waltham, MA, USA), while the peritoneal mesothelial cells were maintained in Dulbecco's modified Eagle's medium (DMEM; Sigma-Aldrich, St. Louis, MO, USA). All of the media were supplemented with $10 \%$ fetal bovine serum (Gibco; Thermo Fisher Scientific, Inc.). All of the cells were subcultured almost every day by $1: 4$ or $1: 5$ dilutions in culture flasks at $37^{\circ} \mathrm{C}$, under an atmosphere of $5 \% \mathrm{CO}_{2}$. Cells that had a cell viability $>90 \%$ in the logarithmic phase were selected for later experimentation. The gastric cancer cells were introduced to the culture flask at a density of $2 \times 10^{6} / \mathrm{ml}$. When the cells reached confluence of $70-80 \%$, they were digested with $0.25 \%$ trypsin (Sigma-Aldrich), washed three times with phosphate-buffered saline (PBS; $\mathrm{pH}, 7.4)$ and then centrifuged at $1,200 \times \mathrm{g}$ for $5 \mathrm{~min}$ to yield cell precipitation.

Semiquantitative reverse transcription polymerase chain reaction $(R T-P C R)$. Total RNA from the cells was isolated using the RNeasy Mini kit following the manufacturer's protocols (Qiagen, Inc., Valencia, CA, USA). The RNA extracted from the gastric cancer cells was reverse-transcribed in a final volume of $20 \mu \mathrm{l}$ using AMV Reverse Transcriptase (Promega Corporation, Madison, WI, USA) according to the manufacturer's protocols with the following system: $1 \mu \mathrm{g}$ oligo(dT) primers, $2 \mu 1$ 10X RT buffer, $2 \mu \mathrm{l}$ deoxynucleotide triphosphate (dNTPs), $4 \mu \mathrm{l} \mathrm{MgCl}_{2}, 0.5 \mu \mathrm{l}$ RNasin, $1 \mu \mathrm{l}$ Oligo(dT) ${ }_{18}$, $0.75 \mu \mathrm{l}$ reverse transcriptase and $1 \mu \mathrm{g}$ RNA. The reactions were performed at $70^{\circ} \mathrm{C}$ for $10 \mathrm{~min}, 42^{\circ} \mathrm{C}$ for $15 \mathrm{~min}, 99^{\circ} \mathrm{C}$ for 15 min and then stored at $4^{\circ} \mathrm{C}$.

Semiquantitative RT-PCR analyses for uPA (16), uPAR (17), PAI-1 (17), $\beta$-actin (18) and glyceraldehyde 3-phosphate dehydrogenase (GAPDH) mRNAs were performed using the Eppendorf MasterCycler ${ }^{\circledR}$ (Eppendorf, Hamburg, Germany). Primers and probes for the TaqMan system were designed using the Primer Premier 5.0 programme (Premier Biosoft International, Palo Alto, CA, USA) and were synthesized by Sangon Biotech Co., Ltd. (Shanghai, China). The sequences of the PCR primer pairs used for each gene are presented in Table I. Semiquantitative RT-PCR was performed with a final volume of $25 \mu \mathrm{l}$ using the following system: $1 \mu \mathrm{l}$ complementary DNA (cDNA), sense and anti-sense primers (each $0.25 \mu \mathrm{l}$ ), $2.5 \mu \mathrm{l}$ 10X PCR buffer, $2 \mu 125 \% \mathrm{MgCl}_{2}, 0.5 \mu \mathrm{l}$ Taq polymerase, $1 \mu \mathrm{ldNTP}$ and $17 \mu \mathrm{l}$ RNase Free $\mathrm{H}_{2} \mathrm{O}$. The amplification conditions were as follows: Initial denaturation at $95^{\circ} \mathrm{C}$ for $5 \mathrm{~min}$, followed by 30 cycles of denaturation at $94^{\circ} \mathrm{C}$ for $1 \mathrm{~min}$, annealing at $56^{\circ} \mathrm{C}$ for $30 \mathrm{sec}$ for uPA, $60^{\circ} \mathrm{C}$ for $1 \mathrm{~min}$ for $\mathrm{UPAR}$ and $55^{\circ} \mathrm{C}$ for $1 \mathrm{~min}$ for PAI-1, and extension at $72^{\circ} \mathrm{C}$ for $1 \mathrm{~min}$. UPA and PAI-1 expression was normalized to the reference gene GAPDH, whilst uPAR was normalized to $\beta$-actin.

Western blot analysis. Cells were washed 3 times with ice-cold PBS and extracted in ice-cold lysis buffer [50 mM Tris- $\mathrm{HCl}$ (pH, 8.0), 1\% Nonidet 40, $0.5 \mathrm{mM}$ ethylenediaminetetraacetic acid, $100 \mu \mathrm{g} / \mathrm{ml}$ phenylmethysulfonyl fluoride, $2 \mu \mathrm{g} / \mathrm{ml}$ leupeptin, $100 \mu \mathrm{m}$ sodium vanadate, $1 \mathrm{mM}$ dithiothreitol, $1 \mu \mathrm{g} / \mathrm{ml}$ aprotinin and $150 \mathrm{mM} \mathrm{NaCl}$ ] for $30 \mathrm{~min}$. An aliquot lysate was used to determine protein concentration using a bicinchoninic acid assay (Pierce Biotechnology, Inc., Rockford, IL, USA). The equal amount of protein per lane was separated on $10 \%$ sodium dodecyl sulfate-polyacrylamide gel and then transferred to a nitrocellulose membrane (EMD Millipore, Billerica, MA, USA). The membrane was blocked with $5 \%$ skimmed milk for $3 \mathrm{~h}$, and was subsequently incubated for $3 \mathrm{~h}$ with monoclonal mouse anti-human uPA antibody (dilution, 1:500; catalog no., TA805243; OriGene Technologies, Inc., Rockville, MD, USA), monoclonal mouse anti-human uPAR antibody (dilution, 1:500; catalog no., sc-376494; Santa Cruz Biotechnology, Inc., Dallas, TX, USA) and monoclonal mouse anti-human PAI-1 antibody (dilution, 1:500; catalog no., sc-5297; Santa Cruz 
Table I. Primers used in the present study.

\begin{tabular}{lclc}
\hline Name & Primer & \multicolumn{1}{c}{ Sequence $\left(5^{\prime}-3^{\prime}\right)$} & Length, bp \\
\hline uPA & Sense & AGAATTCACCACCATCGAGA & 20 \\
& Anti-sense & ATCAGCTTCACAACAGTCAT & 20 \\
uPAR & Sense & ACAGGAGCTGCCCTCGCGAC & 20 \\
& Anti-sense & GAGGGGGATTTCAGGTTTAGG & 18 \\
PAI-1 & Sense & CTTTGGTGAAGGGTCTGC & 19 \\
$\beta$-actin & Anti-sense & CTCCACCTCTGAAAAGTCC & 20 \\
& Sense & TTGAAGGTAGTTTCGGGAAT & 21 \\
GAPDH & Anti-sense & GAAAATCTGGCACCACACCTT & 18 \\
& Sense & GAAGGTGAAGGCGGAGTC & 20 \\
\hline
\end{tabular}

uPA, urokinase-type plasminogen activator; uPAR, uPA receptor; GAPDH, glyceraldehyde 3-phosphate dehydrogenase; PAI-I, plasminogen activator inhibitor-1.

Biotechnology, Inc.), respectively. Following 3 washes with Tris-buffered saline, the membrane was incubated with the goat anti-mouse alkaline phosphatase-conjugated IgG secondary antibody (dilution, 1:5,000; catalog no., sc-2008; Santa Cruz Biotechnology, Inc.). The signal was detected using the NBT/BCIP Reagent kit (Wuhan Huamei Biotech Co., Ltd., Wuhan, China).

Quantitative enzyme-linked immunosorbent assay (ELISA) analysis. UPA, UPAR and PAI-1 antigen concentrations were determined by ELISA kits according to the manufacturer's protocols (American Diagnostica GmbH; Sekisui Diagnostics, Lexington, MA, USA). The reaction was stopped by the addition of $50 \mu \mathrm{l} \mathrm{H}_{2} \mathrm{SO}_{4}$, and the absorption was measured at $450 \mathrm{~nm}$ using the EL312e Automated Microplate reader (BioTek Instruments, Inc., Winooski, VT, USA). The values of the UPA, uPAR and PAI-1 antigen were measured as ng/mg protein.

uPA activity assay. uPA activity in the different cell lines was measured using the ECM600 uPA Activity assay kit (EMD Millipore, Billerica, MA, USA). Following concentration of the cell medium, it was mixed with the assay buffer and subsequently incubated on a chromogenic substrate in 96-well plates at $37^{\circ} \mathrm{C}$, for 2 to $24 \mathrm{~h}$. The optical density (OD) was read at $405 \mathrm{~nm}$, and the activity (units) was extrapolated from a standard curve.

Animal experiments. All procedures in the study were approved by the Institute of Health Services Research at Shanghai East Hospital Affiliated to Tongji University (Shanghai, China) with regard to the protection of animals used for scientific purposes. The manuscript was prepared according to the guidelines of Animal Research, Reporting of In Vivo Experiments (19).

A total of 24 male BALB/C nu/nu rats (220-280 g, 4-5 weeks of age) were utilized in the study. The rats had free access to food and water, and were housed in specific pathogen-free conditions. The rats were randomly divided into 4 groups ( $n=6$ per group) and each group was injected with one type of gastric cancer cell line (MKN28, AGS, MKN45 or SGC7901), with a concentration of $5 \times 10^{6}$ cells in the peritoneal cavity. The rats injected with the cancer cell lines were all injected at the same sites and were observed once a week. Within each group, 1 injected mouse was randomly selected and sacrificed via an intraperitoneal injection of ketamine $(80 \mathrm{mg} / \mathrm{kg})$ at day 14 , while a second rat was sacrificed at day 28 using the same method. The extent of peritoneal metastasis was assessed macroscopically on the rat bodies. Additionally, the survival time of the rats was recorded in each group.

In vitro adhesion assays. In vitro adhesion assays were used to determine the viability of the mesothelial cells, which were cultured with serum-free conditioned media (SF-CM) from the gastric cancer MKN45 cell line with the highest uPA activity. When they reached a satisfactory confluence, the mesothelial cells were digested with $0.25 \%$ trypsin (Sigma-Aldrich) and were seeded in a 24 -well plate with $2 \times 10^{4}$ cells for 12 to $24 \mathrm{~h}$. Meanwhile, the gastric cancer MKN45 cells were resuspended in SF-CM at a density of $1.0 \times 10^{4}$ cells $/ \mathrm{ml}$, followed by incubation with uPA, uPAR and PAI-1 antibodies (each antibody was set with 3 concentrations: $0.1,1$ and $10 \mu \mathrm{g} / \mathrm{ml}$ ) for 45 to $60 \mathrm{~min}$ at $37^{\circ} \mathrm{C}$ under an atmosphere of $5 \% \mathrm{CO}_{2}$. The mesothelial cells were rinsed with SF-CM and were then incubated with antibody-treated gastric cancer cells, with a dilution cell ratio of 1:1. Gastric cancer cells without antibody treatment were used as a control. Following $24 \mathrm{~h}$ of incubation, $50 \mu \mathrm{l}$ methyl thiazolyl tetrazolium (MTT; Sigma-Aldrich) was added and the mixture was incubated at $37^{\circ} \mathrm{C}$ for a further $4 \mathrm{~h}$. Once the mixture had been centrifuged at 2,000 x g for $10 \mathrm{~min}$, the supernatant was discarded. The pellet was dissolved in $400 \mu \mathrm{l}$ dimethyl-sulfoxide and oscillated for $10 \mathrm{~min}$ until the crystals had completely dissolved. The OD at $570 \mathrm{~nm}$ of each well was measured using a microplate reader.

In vitro migration and invasion assays. The invasion and migration abilities of the cells were assayed using non-coated (migration) and Matrigel-coated filters (invasion) using modified 24-well Falcon ${ }^{\mathrm{TM}}$ Cell Culture inserts $(8-\mu \mathrm{m}$ pore size; BD Biosciences, Franklin Lakes, NJ, USA). For the migration assay, the digested mesothelial HMrSV5 cells were seeded at a 
Table II. Relative mRNA expression level of uPA, uPAR and PAI-1 in four gastric cancer cell lines.

\begin{tabular}{lcccc}
\hline uPA system & AGS & SGC7901 & MKN45 & MKN28 \\
\hline uPA & 0.078 & 0.151 & 0.148 & 0.132 \\
uPAR & 0.263 & 0.348 & 0.325 & 0.335 \\
PAI-1 & 0.537 & 0.680 & 0.349 & 0.670 \\
\hline
\end{tabular}

uPA, urokinase-type plasminogen activator; uPAR, uPA receptor; PAI-1, plasminogen activator inhibitor-1.

density of $2 \times 10^{4}$ cells in $0.5 \mathrm{ml}$ DMEM in the upper compartment of Transwell chambers. The gastric cancer MKN45 cells were treated in the same manner as those in the adhesion assay. Following 12 to $24 \mathrm{~h}$ of incubation, the mesothelial HMrSV5 cells were rinsed with SF-CM and were subsequently incubated with antibody-treated gastric cancer cells, with a cell ratio of 1:1. Cancer cells without antibody treatment were used as a control. RPMI-1640 medium with fibronectin and cancer cells were added into the lower chamber as a chemoattractant. Following $72 \mathrm{~h}$ of co-cultivation, MTT was added into the upper and lower compartments for OD detection.

For the invasion assay, Matrigel was washed with SF-CM and added to the upper compartment. The co-cultivation time between the cancer cells and the mesothelial HMrSV5 cells was $48 \mathrm{~h}$.

Statistical analysis. All data were analyzed using SAS 6.12 (SAS Institute, Inc., Cary, NC, USA) and the results were measured as the mean \pm standard deviation. A comparison of the survival time among different groups was performed using post-hoc pair wise comparisons in a one-way analysis of variance. $\mathrm{P}<0.05$ was considered to indicate a statistically significant difference.

\section{Results}

UPA, UPAR and PAI-1 mRNA expression in four gastric cancer cell lines. The RT-PCR amplification products for uPA, uPAR, PAI-1, $\beta$-actin and GAPDH were 474, 1,046, 409, 591 and $230 \mathrm{bp}$, respectively (Fig. 1). Analysis of the uPA system mRNA expression level demonstrated that UPA, uPAR and PAI-1 were all expressed in the four cell lines to varying degrees, and the SGC7901 cells exhibited the highest mRNA expression, whilst the AGS cells demonstrated the lowest mRNA expression (Table II).

UPA, UPAR and PAI-1 protein expression in four gastric cancer cell lines. From the western blotting analysis of the uPA system, it was observed that the level of uPA protein expression was highest in the MKN45 cells, while there was minimal uPA protein expression in the AGS cells (Fig. 2A). There was no expression of UPAR protein in the MKN28 cells, and no difference in the expression of the other three cell lines (Fig. 2B). PAI-1 protein was expressed in all four cell lines, with the MKN28 cells exhibiting the lowest expression level (Fig. 2C).
$\mathbf{A}$

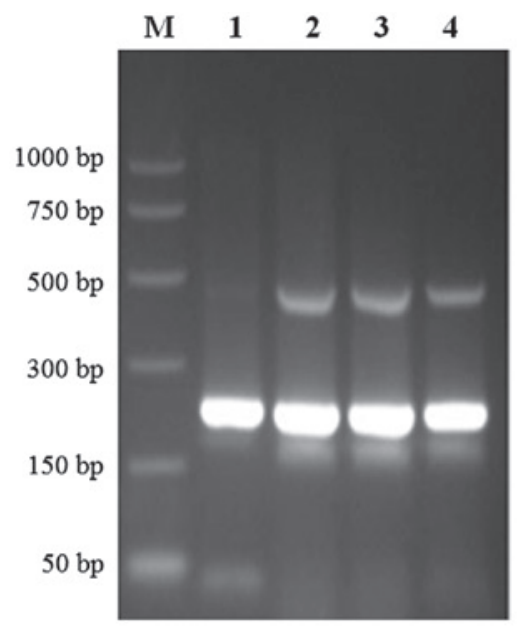

B

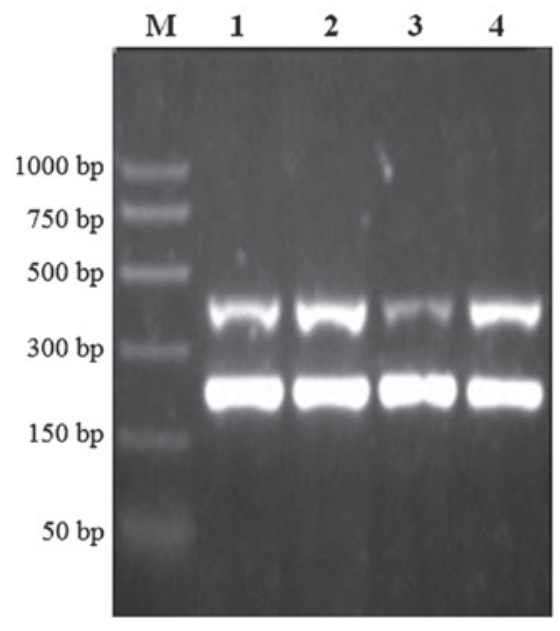

C

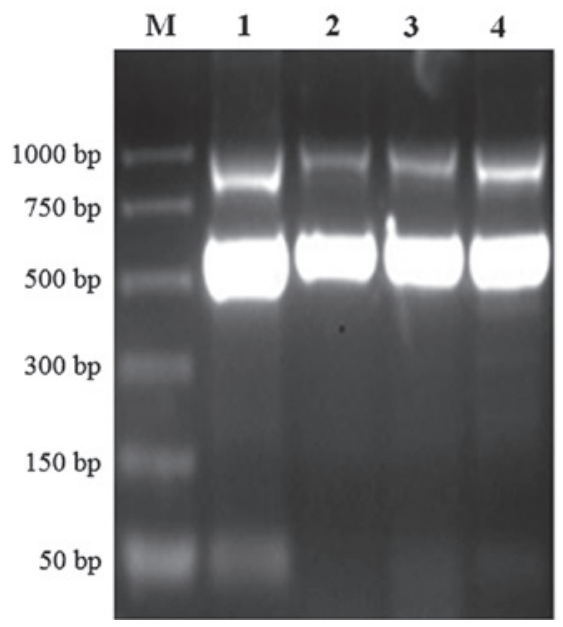

Figure 1. mRNA expression of UPA, uPAR and PAI-1 in four gastric cancer cell lines. (A) uPA, (B) PAI-1 and (C) uPAR. The upper lane in each image represents the UPA, uPAR and PAI-1 expression, respectively, while the lower lane in each image represents the internal reference gene expression. The internal reference gene for UPA and PAI-1 was glyceraldehyde 3-phosphate dehydrogenase, and for uPAR was $\beta$-actin. Lane 1, AGS cell line; lane 2 , SGC7901 cell line; lane 3, MKN45 cell line; and lane 4, MKN28 cell line. M, DNA marker; uPA, urokinase-type plasminogen activator; uPAR, uPA receptor; PAI-1, plasminogen activator inhibitor-1.

UPAR and PAI-1 protein content in culture supernatant and intracellularly in four gastric cancer cell lines. An ELISA assay of the protein content demonstrated that, in supernatant, the uPA protein content was the lowest in the AGS cells. The PAI-1 protein content was the lowest in the 
Table III. Protein content of uPA, uPAR and PAI-1 in supernatant and intracellular.

\begin{tabular}{|c|c|c|c|c|c|}
\hline \multirow[b]{2}{*}{ Cell lines } & \multicolumn{3}{|c|}{ Supernatant, ng/mg } & \multicolumn{2}{|c|}{ Intracellular, ng/mg } \\
\hline & uPA & uPAR & PAI-1 & uPA & PAI-1 \\
\hline AGS & 0.043 & 0.892 & 76.465 & 0.038 & 14.083 \\
\hline SGC7901 & 0.195 & 11.648 & 108.067 & 0.483 & 37.289 \\
\hline MKN45 & 0.070 & 1.765 & 87.294 & 0.582 & 10.133 \\
\hline MKN28 & 0.059 & ND & 0.491 & 0.189 & ND \\
\hline
\end{tabular}

uPA, urokinase-type plasminogen activator; uPAR, uPA receptor; PAI-1, plasminogen activator inhibitor-1; ND, no detection.

A

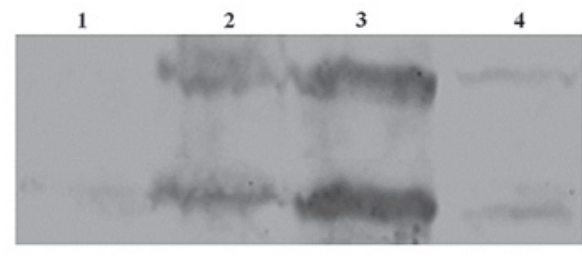

B

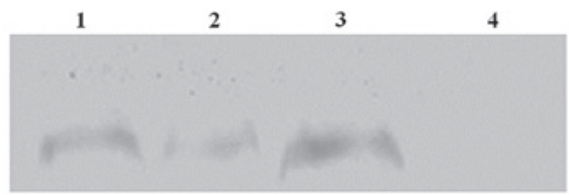

C

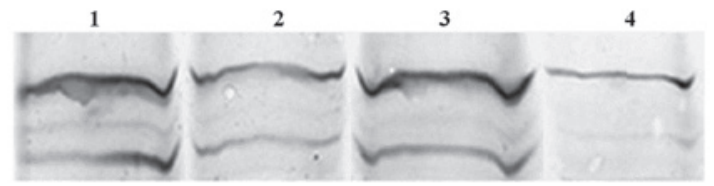

D

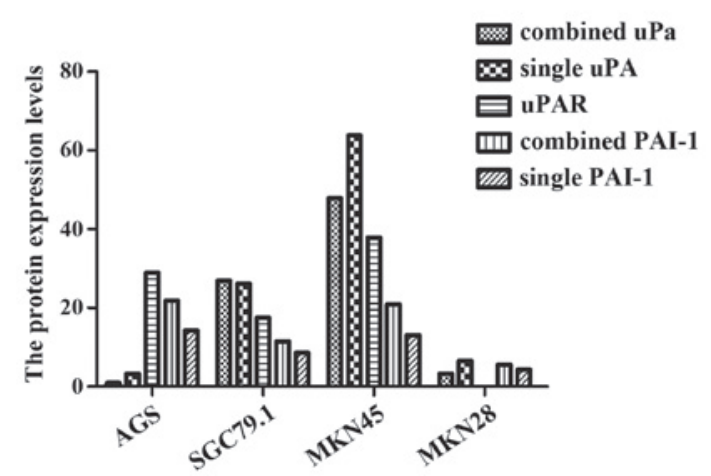

Figure 2. uPA, uPAR and PAI-1 protein expression in four gastric cancer cell lines: (A) uPA $(60 \mathrm{kDa})$, the upper lane demonstrates the expression of combined UPA, and the lower lane is the expression of single uPA (52 kDa); (B) uPAR (60 kDa); (C) PAI-1, the upper lane is the expression of combined PAI-1 (60 kDa), and the lower lane is the expression of single PAI-1 (47 kDa). (D) Protein expression levels of combined uPA, single uPA, uPAR, combined PAI-1 and single PAI-1 the four gastric cancer cell lines. Lane 1, AGS cell line; lane 2, SGC7901 cell line; lane 3, MKN45 cell line; lane 4, MKN28 cell line; M, DNA marker; uPA, urokinase-type plasminogen activator; uPAR, uPA receptor; PAI-1, plasminogen activator inhibitor-1.

MKN28 cells, and there was no detection of uPAR in this cell line. Intracellularly, uPA expression was highest in the MKN45 cells, while there was no detection of PAI-1 in the MKN28 cells. Additionally, PAI-1 expression was highest in the SGC7901 cells when compared with the other three cell lines (Table III).

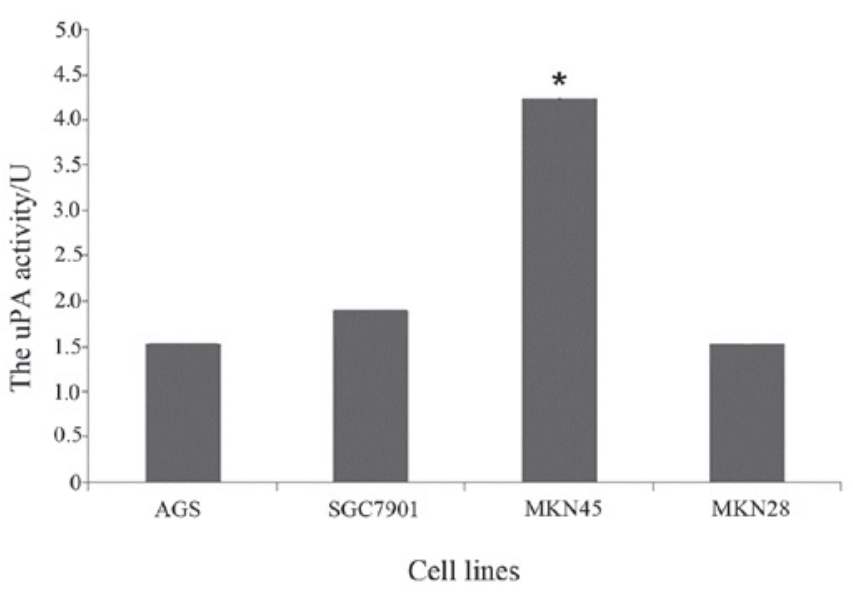

Figure 3. uPA activity in the four cell lines. uPA, urokinase-type plasminogen activator. ${ }^{*} \mathrm{P}<0.05$.

uPA activity detection. The uPA activities of the four cell lines were 1.531 units in the AGS cells, 1.904 units in the SGC7901 cells, 4.283 units in the MKN45 cells and 1.541 units in the MKN28 cells. Furthermore, the highest uPA activity was observed in the MKN45 cells, whilst the lowest was observed in the AGS cells (Fig. 3), and the uPA activity of SGC7901 cells was significantly higher than that of the other 3 cell lines $(\mathrm{P}<0.05)$.

Peritoneal tumor development following injection with different cell lines. Peritoneal tumor development was altered following injection with the four cell lines. The time to peritoneal tumor occurrence was different in each cell line, with tumors occurring at $\sim 1$ week in the MKN45 cells and $\sim 10$ days in the SGC7901 and MKN28 cells, while no peritoneal tumor was identified in the AGS cells, even at 28 days post-injection (Fig. 4A and B). The tumor masses in the SGC7901 and MKN45 cells were observed in similar conditions; the sizes of the masses varied and were scattered over the whole abdominal cavity, but they were primarily located in the omentum and pelvic cavity, and no ascites was produced (Fig. 4C-H). Tumor masses in the MKN28 cells were of a similar size and were primarily distributed on the mesentery; hemorrhagic ascites also developed during the first week subsequent to injection and progressed in a time-dependent manner (Fig. 4G and H).

Survival time of rats following injection with different cell lines. Following injection with the gastric cancer cell lines, 
A

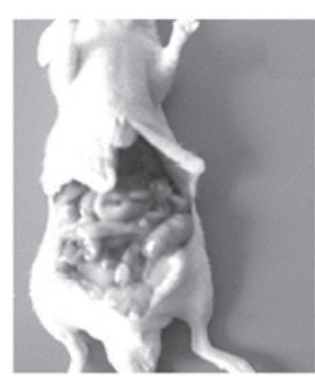

AGS (14 days)

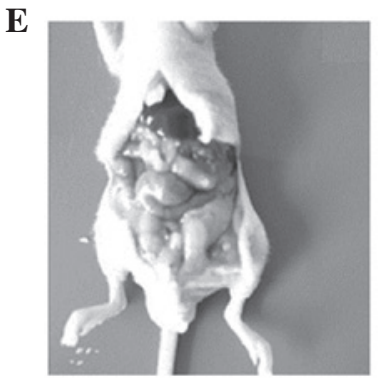

MKN45 (14 days)
B

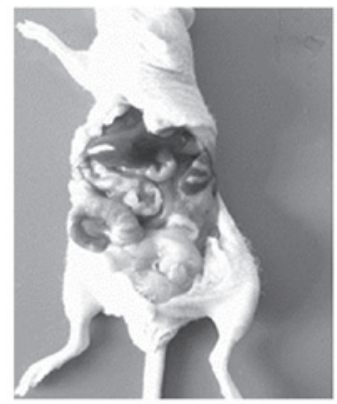

AGS (28 days)

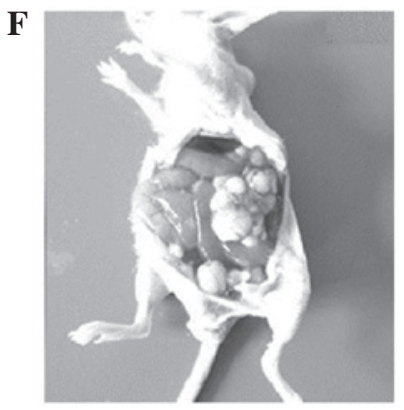

MKN45 (28 days)

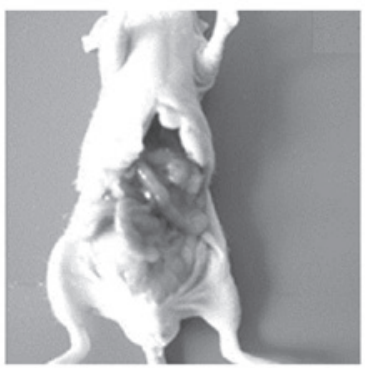

SGC7901 (14 days)

G

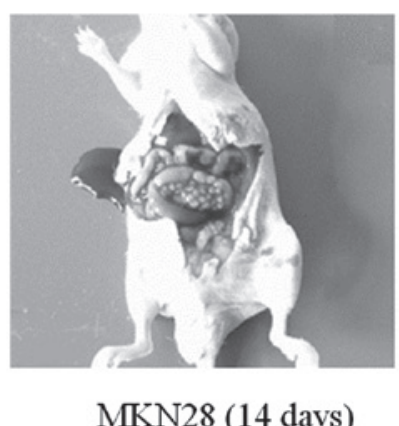

D

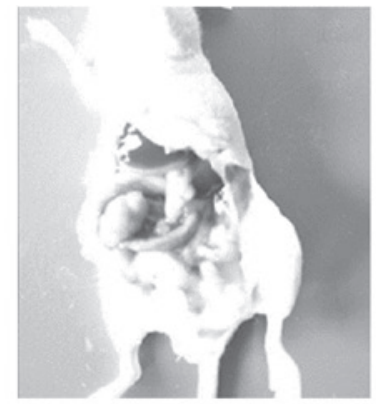

SGC7901 (28 days)

H

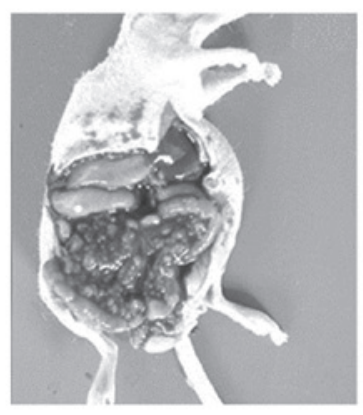

MKN28 (28 days)

Figure 4. Peritoneal tumor development at varying time points in rats following injection with different cell lines. (A and B) AGS cell line at 14 and 28 days respectively, exhibiting no peritoneal tumor; (C) SGC7901 cell line at 14 days, with a 1-2-mm tumor in the omentum majus; (D) SGC7901 cell line at 28 days (largest tumor size, $\sim 5 \mathrm{~mm}$ ); (E) MKN45 cell line at 14 days, with a tumor similar to that observed in the SGC7901 cell-injected rats; (F) MKN45 cell line at 28 days, with a tumor similar to that observed in the SGC7901 cell-injected rats; (G) MKN28 cell line at 14 days, with a 0.5 -mm tumor in the mesentery, and hemorrhagic ascites; and (H) MKN28 cell line at 28 days, with a 1-mm tumor in the mesentery, and hemorrhagic ascites.

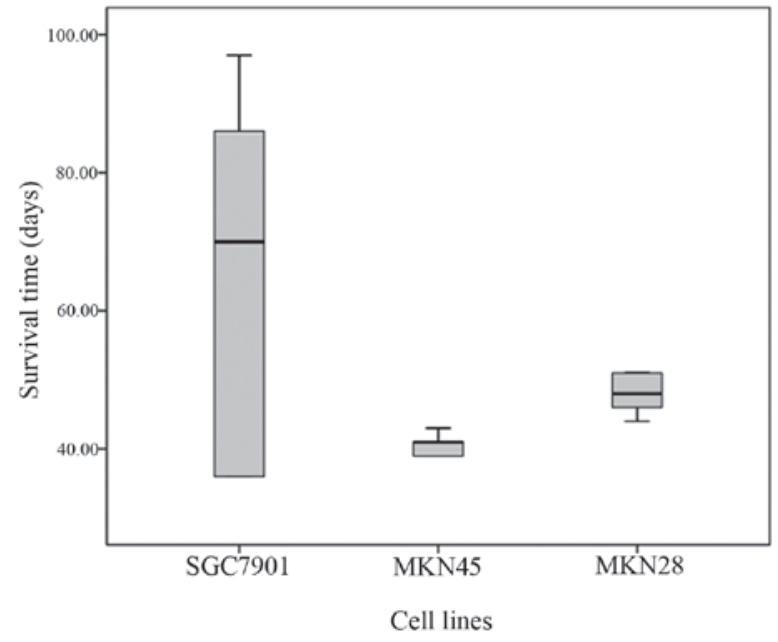

Figure 5. Survival time (days) of rats following injection with different cell lines. MKN45 vs. MKN28, P=0.0041; SGC7901 vs. MKN45, P=0.5970.

the rats that were injected with the AGS cells all survived. The median survival time of rats injected with the MKN45 cells was the shortest, at just 41 days (Table IV). Additionally, the survival time of the SGC7901 and the MKN28-injected rats was longer than that of the MKN45-injected rats, and there was no significant difference between the two groups $(\mathrm{P}=0.5970)$. The difference between the MKN45 and the MKN28-injected rats was significant $(\mathrm{P}=0.0041)$. When compared with the MKN45-injected rats, the survival time of all rats injected with the SGC7901 cells was varied (range, 36-97 days; Fig. 5).
Adhesion, migration and invasion assays in vitro. The OD of the MKN45 cells amongst the mesothelial cells in the rats gradually declined with an increasing concentration of uPA system antibodies (Fig. 6). MTT analysis demonstrated that the OD value was in proportion with the live cell numbers. The results indicate that adhesion and migration of the MKN45 cells to the mesothelial cells decreased due to the inhibitory effect of the uPA system antibodies (Fig. 6A and B). When compared with the control, uPAR and PAI-1 antibodies appeared to promote adhesion between the MKN45 cells and the mesothelial cells (Fig. 6). Notably, the inhibitory effects of the UPAR and PAI-1 antibodies on adhesion and migration were more potent than that of the uPA antibody at the same concentration (Fig. 6A and B). Additionally, a lower concentration of the uPA system antibodies $(0.1 \mu \mathrm{g} / \mathrm{ml})$ had a greater effect on the adhesion and migration of the MKN45 cell line compared with a higher concentration (1 and $10 \mu \mathrm{g} / \mathrm{ml})$. However, the uPA system antibody inhibited the migration of the MKN45 cell line at a low concentration, and this effect was enhanced in a concentration-dependent manner (Fig. 6A and B).

Notably, although the uPA system antibodies did induce invasion inhibition, this effect did not appear to be associated with the antibody concentration (Fig. 6C).

\section{Discussion}

Gastric cancer is one of the leading causes of cancer-associated mortality worldwide (1), and is responsible for large numbers of novel cancer cases and fatalities every year (20). Although surgery and adjuvant chemotherapy have resulted in superior periodical survival for gastric cancer patients, 
Table IV. Survival time (days) of rats following injection with different cell lines.

\begin{tabular}{lcccccc}
\hline & \multicolumn{5}{c}{ Nude mice } \\
\cline { 2 - 7 } Cell line & 1 & 2 & 3 & 4 & 5 & Median \\
\hline SGC7901 & 36 & 36 & 70 & 86 & 97 & 70 \\
MKN45 & 35 & 39 & 41 & 41 & 43 & 41 \\
MKN28 & 44 & 46 & 48 & 51 & 69 & 48
\end{tabular}

The numbers 1-5 represent the serial number of the nude mice in each cell line. Median, median survival time.
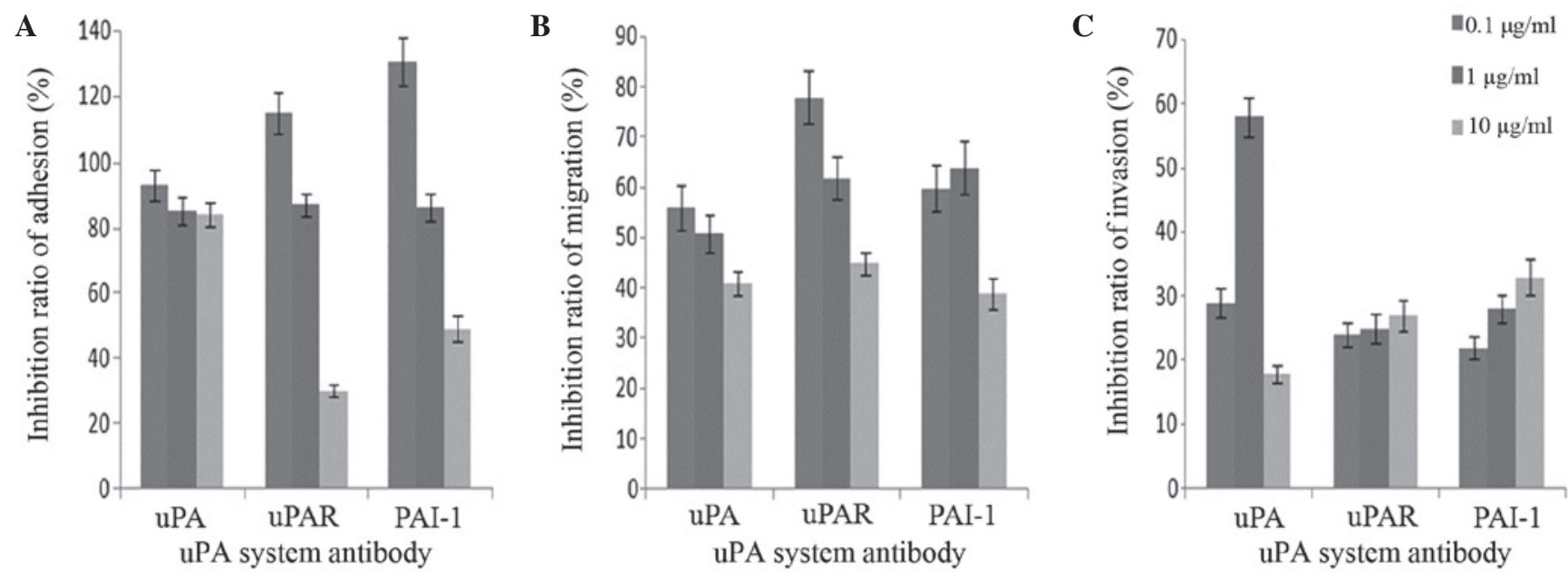

Figure 6. Inhibition percentage of the uPA system on biological behaviors in the MKN45 cells. (A) Inhibition percentage of the uPA system on adhesion. (B) Inhibition percentage of the uPA system on migration. (C) Inhibition percentage of the uPA system on invasion. uPA, urokinase-type plasminogen activator; uPAR, uPA receptor; PAI-1, plasminogen activator inhibitor-1.

relapse is particularly common $(21,22)$. Numerous studies have reported that the uPA system serves an important role in various types of cancer, including breast, lung, liver and pancreatic cancer (23-25). In the present study, the functions of the uPA system in the peritoneal metastasis of gastric cancer was analyzed. The expression of the uPA system in four types of gastric cancer cells (AGS, SGC7901, MKN45 and MKN28) appeared to vary. The highest level of uPA system expression and UPA activity was observed in the SGC7901 cells. Peritoneal implantation analysis demonstrated that no tumors in the peritoneum were observed in the AGS-injected rats, and the tumor masses were of different sizes in the SGC7901 and MKN45-injected rats. The survival times of the rats injected with the MKN28 and SGC7901 cells were longer than those observed in the rats injected with the MKN45 cells. Antibodies of the uPA system were able to inhibit the adhesion, migration and invasion to the peritoneum in the gastric cancer MKN45 cell line, with the strongest peritoneal implantation.

The invasion and metastasis of tumors is a complex process, involving adhesion, alterations in tumor cell polarity, and degradation and reconstruction of the ECM (26). The adhesion between gastric cancer cells and mesothelial cells is crucial for the formation of peritoneal metastasis. Mesothelial cells are the primary component of the peritoneum (27). Following adhesion onto peritoneal tissue, gastric cancer cells that have interacted with proteolytic enzymes may migrate into the ECM via mesothelial cells (28). The hydrolysis of the ECM by a malignant tumor is a necessity for tumor migration and invasion, which involves numerous proteolytic enzymes. As it contains important proteolytic enzymes, the uPA system has been demonstrated to be a key enzyme system in mediating tumor metastasis $(29,30)$. uPA, pro-uPA, uPAR and PAI are the members of the uPA system (13), which primarily participate in plasminogen activation and ECM degradation. Overwhelming evidence from previous studies has demonstrated that the cell surface-associated uPA/uPAR complex is involved in the tumor invasion and metastasis of several types of cancer, functioning through direct or indirect interactions with integrins and growth factors $(31,32)$.

uPA may only activate plasminogens once it has specifically combined with UPAR existing on the surface of the cytomembrane (13). Shimizu et al (23) demonstrated that downregulation of the uPA system, inhibited by Jagged-1-induced Notch, inhibits the progression of breast cancer (23). Li et al (33) reported that the downregulation of uPA, inhibited by microRNA193b, can prevent the invasion between MDA-MB-231 and MDA-MB-435 cells in human breast cancer. uPA interacts with its corresponding receptor to affect cell adhesion and migration, and uPA allows for cross-talk between uPAR and $\alpha \mathrm{M} \beta 2$ integrins on peripheral blood neutrophils that express these two receptors (34). In the present study, the uPA activity in the MKN45 cells was 
higher than that observed in the other cell lines, and uPA antibody inhibited cell adhesion and migration, indicating that uPA serves a key role in cell adhesion and migration in cancer. Additionally, the uPA antibody inhibited the adhesion and migration of the MKN45 cell line to the mesothelial cells, suggesting that uPA may contribute to the adhesion of MKN45 cells in gastric cancer in the peritoneum.

UPAR mediates the signaling transduction of uPA and has an impact on cell proliferation, chemotaxis, migration and differentiation. In tumor cell adhesion, uPAR inhibits the combination of cells and fibrinogen by bonding with integrins attached to the cytoskeleton; once bound, uPAR alters the specificity of the cell adhesion matrix (35). Koochekpour et al (31) demonstrated that the upregulation of the UPA/uPAR system, activated by saposin $\mathrm{C}$, accelerated cell growth and invasion via the p42/44 mitogen-activated protein kinase (MAPK) signaling pathway (31). The regulatory effect of UPAR may be exerted through the activation of MAPK, and its overexpression can increase uPA secretion in uPAR-expressing cells, involving its functional interaction with integrins and fMet-Leu-Phe receptors (36). Grove et al (37) observed that UPAR ligation with the urokinase receptor binding domain (amino-terminal fragment) results in enhanced migration of fibroblasts on fibronectin in a protease-independent, lipid raft-dependent manner. Nowicki et al (38) demonstrated that the downregulation of uPA inhibited the phosphatidylinositol 3-kinase and Akt signaling pathways, which led to the migration of glioblastoma cells. The interaction between UPAR and the uPA complex affects tumor progression, invasion and migration (39). Thus, limiting the combination of uPAR and uPA may be an important method for cancer treatment. In the present study, the expression level of uPAR was observed to be higher in the MKN45 cells when compared with the other cell lines, and the UPAR antibody inhibited MKN45 cell adhesion and migration, suggesting that UPAR may promote the adhesion and migration of MKN45 cells to mesothelial cells.

There are three inhibitors for uPA within the uPA system: PAI-1, PAI-2 and PAI-3. PAI-1 is typically the key inhibitor of human plasma uPA, and it is activated during the initial synthesis stage, but is rapidly inactivated when in serum (40). Immunohistochemical analysis demonstrated that PAI-1 was associated with lymphatic metastasis and cooperated with uPA to serve a role in the invasion and migration of tumor cells (41). The upregulation of PAI-1 limits the accumulation of plasmin, as well as the activation of matrix metalloproteinase (MMP)-2 and -9 in prostate cancer (39). Huber et al (42) observed that the increased expression of PAI-1, activated by the proinflammatory cytokine tumor necrosis factor $\alpha$, restricted the invasion of HTR-8/SVneo cells (42). The results of the present study demonstrated that the PAI-1 antibody exhibited greater inhibition of MKN45 cell invasion compared with adhesion and migration; thus suggesting that PAI-1 primarily functions during the invasive tumor cell stage, and may contribute to gastric cancer adhesion and migration. Notably, the effect of the uPA system on the invasive ability of the MKN45 cells demonstrated no significance among antibodies with different concentrations. However, the effect of PAI-1 antibody concentration on gastric cancer cell behaviors has not been fully investigated. Thus, further research is required to investigate the effect of antibody concentration on gastric cancer cells.
In conclusion, the present study examined the association between the uPA system and peritoneal metastasis in gastric cancer. The MKN45 cell line has a high level of uPA system expression, as well as uPA activity. Proteins in the uPA system may inordinately promote the adhesion, migration and invasion of tumor cells into mesothelial cell layers. The results of the current study may provide guidelines for the use of the uPA system in gastric cancer diagnosis, and may hopefully provide a basis for the development of uPA therapy options to treat gastric cancer with peritoneal metastasis.

\section{References}

1. Ferro A, Peleteiro B, Malvezzi M, Bosetti C, Bertuccio P, Levi F, Negri E, La Vecchia $C$ and Lunet N: Worldwide trends in gastric cancer mortality (1980-2011), with predictions to 2015, and incidence by subtype. Eur J Cancer 50: 1330-1344, 2014.

2. Kanda M, Shimizu D, Nomoto S, Takami H, Hibino S, Oya H, Hashimoto R, Suenaga M, Inokawa Y, Kobayashi D, et al: Prognostic impact of expression and methylation status of DENN/MADD domain-containing protein 2D in gastric cancer. Gastric Cancer 18: 288-296, 2015.

3. Fujii S, Kitayama J, Kaisaki S, Sasaki S, Seto Y, Tominaga O, Tsuno $\mathrm{N}$, Umetani $\mathrm{N}$, Yokota $\mathrm{H}$, Kitamura $\mathrm{K}$, et al: Carcinoembryonic antigen mRNA in abdominal cavity as a useful predictor of peritoneal recurrence of gastric cancer with serosal exposure. J Exp Clin Cancer Res 21: 547-553, 2002.

4. Zhao P, Lu Y, Jiang X and Li X: Clinicopathological significance and prognostic value of CD133 expression in triple-negative breast carcinoma. Cancer Sci 102: 1107-1111, 2011.

5. Thompson EW, Newgreen DF and Tarin D: Carcinoma invasion and metastasis: A role for epithelial-mesenchymal transition? Cancer Res 65: 5991-5995, 2005.

6. Cho RW and Clarke MF: Recent advances in cancer stem cells. Curr Opin Genet Dev 18: 48-53, 2008

7. John A and Tuszynski G: The role of matrix metalloproteinases in tumor angiogenesis and tumor metastasis. Pathol Oncol Res 7: 14-23, 2001.

8. Steeg PS: Tumor metastasis: Mechanistic insights and clinical challenges. Nat Med 12: 895-904, 2006.

9. Fenoglio-Preiser C, Carneiro F, Correa P, Guildford P, Lambert R, Megraud F, Muñoz N, Powell SM, Rugge M, Sasako M, et al (eds): Gastric carcinoma. In: World Health Organisation Classification of Tumours. Pathology and Genetics of Tumours of the Digestive System. IARC Press, Lyon, pp35-52, 2000.

10. Crippa MP: Urokinase-type plasminogen activator. Int J Biochem Cell Biol 39: 690-694, 2007.

11. Look MP, van Putten WL, Duffy MJ, Harbeck N, Christensen IJ, Thomssen C, Kates R, Spyratos F, Fernö M, Eppenberger-Castori S, et al: Pooled analysis of prognostic impact of urokinase-type plasminogen activator and its inhibitor PAI-1 in 8377 breast cancer patients. J Natl Cancer Inst 94: 116-128, 2002.

12. Pulukuri SMK and Rao JS: Small interfering RNA directed reversal of urokinase plasminogen activator demethylation inhibits prostate tumor growth and metastasis. Cancer Res 67: 6637-6646, 2007.

13. Dass K, Ahmad A, Azmi AS, Sarkar SH and Sarkar FH: Evolving role of uPA/uPAR system in human cancers. Cancer Treat Rev 34: 122-136, 2008.

14. Kaneko T, Konno H, Baba M, Tanaka T and Nakamura S: Urokinase-type plasminogen activator expression correlates with tumor angiogenesis and poor outcome in gastric cancer. Cancer Sci 94: 43-49, 2003

15. Lee DH, Yang Y, Lee SJ, Kim KY, Koo TH, Shin SM, Song KS, Lee YH, Kim YJ, Lee JJ, et al: Macrophage inhibitory cytokine-1 induces the invasiveness of gastric cancer cells by up-regulating the urokinase-type plasminogen activator system. Cancer Res 63: 4648-4655, 2003.

16. Champelovier P, Boucard N, Levacher G, Simon A, Seigneurin D and Praloran V: Plasminogen- and colony-stimulating factor-1-associated markers in bladder carcinoma: Diagnostic value of urokinase plasminogen activator receptor and plasminogen activator inhibitor type-2 using immunocytochemical analysis. Urol Res 30: 301-309, 2002. 
17. Rosanò L, Varmi M, Salani D, Di Castro V, Spinella F, Natali PG and Bagnato A: Endothelin-1 induces tumor proteinase activation and invasiveness of ovarian carcinoma cells. Cancer Res 61: 8340-8346, 2001.

18. Yonemura Y,Fujimura T, Ninomiya I, Kim BS, Bandou E, Sawa T, Kinoshita K, Endo Y, Sugiyama K and Sasaki T: Prediction of peritoneal micrometastasis by peritoneal lavaged cytology and reverse transcriptase-polymerase chain reaction for matrix metalloproteinase-7 mRNA. Clin Cancer Res 7: 1647-1653, 2001

19. Kilkenny C, Browne W, Cuthill IC, Emerson M and Altman DG; NC3Rs Reporting Guidelines Working Group: Animal research Animal research: Reporting in vivo experiments: the ARRIVE guidelines. Br J Pharmacol 160: 1577-1579, 2010.

20. Siegel R, Naishadham D and Jemal A: Cancer statistics, 2013. CA Cancer J Clin 63: 11-30, 2013

21. Japanese Gastric Cancer Association: Japanese gastric cancer treatment guidelines 2010 (ver. 3). Gastric Cancer 14: 113-123, 2011.

22. Kang JH, Lee SI, Lim DH, Park KW, Oh SY, Kwon HC, Hwang IG, Lee SC, Nam E, Shin DB, et al: Salvage chemotherapy for pretreated gastric cancer: A randomized phase III trial comparing chemotherapy plus best supportive care with best supportive care alone. J Clin Oncol 30: 1513-1518, 2012.

23. Shimizu M, Cohen B, Goldvasser P, Berman H, Virtanen C and Reedijk M: Plasminogen activator UPA is a direct transcriptional target of the JAG1-Notch receptor signaling pathway in breast cancer. Cancer Res 71: 277-286, 2011.

24. Qiu X, Guo S, Wu H, Chen J and Zhou Q: Identification of Wnt pathway, uPA, PAI-1, MT1-MMP, S100A4 and CXCR4 associated with enhanced metastasis of human large cell lung cancer by DNA microarray. Minerva Med 103: 151-164, 2012.

25. Berasain C, Ujue Latasa M, Urtasun R, Goñi S, Elizalde M, Garcia-Irigoyen O, Azcona M, Prieto J and Ávila MA: Epidermal growth factor receptor (EGFR) crosstalks in liver cancer Cancers (Basel) 3: 2444-2461, 2011.

26. Valastyan S and Weinberg RA: Tumor metastasis: Molecular insights and evolving paradigms. Cell 147: 275-292, 2011.

27. Mutsaers SE: The mesothelial cell. Int J Biochem Cell Biol 36: 9-16, 2004

28. Na D, Liu FN, Miao ZF, Du ZM and Xu HM: Astragalus extract inhibits destruction of gastric cancer cells to mesothelial cells by anti-apoptosis. World J Gastroenterol 15: 570-577, 2009.

29. Danø K, Behrendt N, Høyer-Hansen G, Johnsen M, Lund LR, Ploug $\mathrm{M}$ and Rømer J: Plasminogen activation and cancer. Thromb Haemost 93: 676-681, 2005.

30. Mekkawy AH, Morris DL and Pourgholami MH: Urokinase plasminogen activator system as a potential target for cancer therapy. Future Oncol 5: 1487-1499, 2009.

31. Koochekpour S, Sartor O, Hiraiwa M, Lee TJ, Rayford W, Remmel N, Sandhoff K, Minokadeh A and Patten DY: Saposin C stimulates growth and invasion, activates p42/44 and SAPK/JNK signaling pathways of MAPK and upregulates uPA/uPAR expression in prostate cancer and stromal cells J Androl 7: 147-158, 2005.
32. Binder BR, Mihaly J and Prager GW: uPAR-uPA-PAI-1 interactions and signaling: A vascular biologist's view. Thromb Haemost 97: 336-342, 2007.

33. Li XF, Yan PJ and Shao ZM: Downregulation of miR-193b contributes to enhance urokinase-type plasminogen activator (uPA) expression and tumor progression and invasion in human breast cancer. Oncogene 28: 3937-3948, 2009.

34. Pluskota E, Soloviev DA and Plow EF: Convergence of the adhesive and fibrinolytic systems: Recognition of urokinase by integrin alpha Mbeta 2 as well as by the urokinase receptor regulates cell adhesion and migration. Blood 101: 1582-1590, 2003.

35. Blasi F and Sidenius N: The urokinase receptor: Focused cell surface proteolysis, cell adhesion and signaling. FEBS Lett 584: 1923-1930, 2010.

36. Montuori N, Cosimato V, Rinaldi L, Rea VEA, Alfano D and Ragno P: uPAR regulates pericellular proteolysis through a mechanism involving integrins and $\mathrm{MLF}$-receptors. Thromb Haemost 109: 309-318, 2013

37. Grove LM, Southern BD, Jin TH, White KE, Paruchuri S, Harel E, Wei Y, Rahaman SO, Gladson CL, Ding Q, et al: Urokinase-type plasminogen activator receptor (uPAR) ligation induces a raft-localized integrin signaling switch that mediates the hypermotile phenotype of fibrotic fibroblasts. J Biol Chem 289: 12791-12804, 2014.

38. Nowicki TS, Zhao H, Darzynkiewicz Z, Moscatello A, Shin E, Schantz S, Tiwari RK and Geliebter J: Downregulation of uPAR inhibits migration, invasion, proliferation, FAK/PI3K/Akt signaling and induces senescence in papillary thyroid carcinoma cells. Cell Cycle 10: 100-107, 2011.

39. Sheng S: The urokinase-type plasminogen activator system in prostate cancer metastasis. In: Prostate Cancer: New Horizons in Research and Treatment. Cher ML, Honn KV and Raz A (eds). Springer, pp151-160, 2002.

40. Francis RM, Romeyn CL, Coughlin AM, Nagelkirk PR, Womack CJ and Lemmer JT: Age and aerobic training status effects on plasma and skeletal muscle tPA and PAI-1. Eur J Appl Physiol 114: 1229-1238, 2014.

41. Malinowsky K, Wolff C, Berg D, Schuster T, Walch A, Bronger H, Mannsperger H, Schmidt C, Korf U, Höfler H, et al: uPA and PAI-1-related signaling pathways differ between primary breast cancers and lymph node metastases. Transl Oncol 5: 98-104, 2012.

42. Huber AV, Saleh L, Bauer S, Husslein P and Knöfler M: TNFalpha-mediated induction of PAI-1 restricts invasion of HTR-8/SVneo trophoblast cells. Placenta 27: 127-136, 2006. 